\title{
Implementasi RCM pada mesin diesel Deutz 20 kVA
}

\author{
Sunaryo ${ }^{1}$, Japri $^{2}$, Yuhelson 3 , Legisnal Hakim ${ }^{4}$ \\ 1,2,3,4Program Studi Teknik Mesin, Fakultas Teknik, Universitas Muhammadiyah Riau \\ Jalan Tuanku Tambusai Ujung, Kecamatan Tampan, Kelurahan Delima, Kota \\ Pekanbaru, Riau 28291 \\ *corresponding author: sunaryo@umri.ac.id
}

\begin{abstract}
The aspect that most influences the functioning of this telecommunications service is the aspect of maintaining the equipment or assets supporting the telecommunications service. For this reason, companies must periodically measure the performance of their maintenance so that telecommunications services continue to function properly. From the data, the frequency of damage to the diesel generator engine from 2017 to 2020 is very high. In the period 2017 to 2020 there were a total of 90 times the damage, and the biggest contributor to the damage was in the 20kVA Deutz diesel engine. The purpose of this research is to know how the maintenance conditions are and to know the level of effectiveness and to know the right recommendations to increase the effectiveness of the diesel generator engine. The research method used is RCM (Reliability Centered maintanance) which is a technique used to develop scheduled preventive maintenance. Research results obtained, the component whose frequency is often damaged in the Deutz generator diesel engine is the Alternator. This selection is based on the highest number of damage frequencies and the longest downtime for approximately 3 years. Calculation of the Alternator's Mean Time to Failure (MTTF) value is 25305 hours, which means that the Alternator component will experience damage again after operating for 25305 hours. While the Mean Time to Repair (MTTR) value of the Alternator is 22.54 hours, which means that the average time to repair the Alternator component is 22.54 hours. From the calculation of the Reliability Value, the alternator is said to still have a good function because the average value interval is still in the range $0<R(t)<1$. From the analysis results obtained the value of $\beta$ of 1.64205 . With this value $(\beta>1)$, the appropriate types of maintenance for the Alternator component are Preventive and Time Based Maintenance.
\end{abstract}

Keywords: Reliability Centered Maintenance, Critical Components, Maintenance.

\begin{abstract}
Abstrak
Aspek yang paling berpengaruh terhadap berfungsinya layanan telekomunikasi ini adalah aspek perawatan perangkat atau asset pendukung layanan telekomunikasi tersebut. Untuk itu, perusahaan harus secara berkala mengukur kinerja perawatannya agar layanan telekomunikasi tetap berfungsi dengan baik. Dari data frekwensi kerusakan pada mesin diesel genset tahun 2017 sampai dengan 2020 yang sangat tinggi. Pada periode tahun 2017 sampai dengan 2020 ada total kerusakan sebanyak 90 kali, dan penyumbang kerusakan terbesar ada di mesin diesel Deutz kapasitas 20kVA. Tujuan dari penelitian ini adalah untuk mengetahui bagaimana kondisi maintenance dan mengetahui tingkat efektivitas serta mengetahui rekomendasi yang tepat untuk meningkatkan efektivitas dari mesin diesel genset tersebut. Metode penelitian yang digunakan adalah RCM (Reliability Centered maintanance) yang merupakan suatu teknik yang dipakai untuk mengembangkan preventive maintenance yang terjadwal. Hasil penelitian didapat, komponen yang frekuensinya sering mengalami kerusakan pada mesin diesel genset deutz adalah Alternator. Pemilihan ini didasarkan pada jumlah frekuensi kerusakan tertinggi serta downtime terlama selama kurang lebih 3 tahun. Perhitungan nilai Mean Time to Failure (MTTF) Alternator adalah 25305 jam yang artinya
\end{abstract}


komponen Alternator akan mengalami kerusakan kembali setelah beroperasi selama 25305 jam. Sedangkan nilai Mean Time to Repair (MTTR) dari Alternator adalah 22,54 jam yang artinya rata-rata waktu untuk perbaikan komponen Alternator selama 22,54 jam. Dari hasil perhitungan Nilai Kehandalan, Alternator dikatakan masih memiliki fungsi dengan baik karena interval nilai rata - rata nya masih di range $0<\mathrm{R}(\mathrm{t})<1$. Dari hasil analisa didapat nilai $\beta$ sebesar 1,64205 . Dengan nilai tersebut $(\beta>1)$ maka jenis pemeliharaan yang sesuai pada komponen Alternator adalah Preventive dan Time Based Maintenance.

Kata kunci: Reliability Centered Maintanance, Komponen Kritis, Perawatan.

\section{Pendahuluan}

Salah satu asset pendukung dan sangat berpengaruh terhadap berfungsinya layanan telekomunikasi adalah kualitas / kehandalan perangkat electrical power system atau energi listrik. Dapat diketahui bahwa dalam sistem distribusi tenaga listrik baik Perusahaan Listrik Negara (PLN) maupun generator set (Genset) tidaklah mungkin dapat menyediakan tenaga listrik secara mutlak tanpa adanya gangguan atau kerusakan. Oleh karena itu dibutuhkan perawatan / maintenance mesin diesel yang baik dan benar dan diharapkan bisa menjaga kelanjutan operasional penyediaan pembangkit tenaga listrik di perangkat telekomunikasi. Perawatan (maintenance) mencakup semua aktivitas yang berkaitan dalam mempertahankan peralatan sistem agar tetap bekerja [1].

Pengawasan bukanlah tindakan semata-mata mencari kesalahan, tetapi justru bersikap membantu petugas perawatan agar tidak berbuat kekeliruan/kesalahan atau hal-hal lain yang dapat mengakibatkan kerusakan berat. Sebab, bila terjadi kerusakan yang mengalami kerugian bukan saja perusahaan tetapi juga masyarakat pada umumnya [2].

Data kerusakan mesin diesel genset yang sudah diambil di PT Telkomsel Cluster Network Operation RTPO Tembilahan, frekuensi jumlah total kerusakan nya mesin diesel nya sebanyak 90 kali dan penyumbang terbesar kerusakan mesin diesel genset adalah genset Merk DEUTZ 20kVA dengan prosentase kerusakannya sebesar $54.44 \%$. 20kVA. RCM (Reliability Centered maintanance) merupakan suatu teknik yang dipakai untuk mengembangkan preventive maintenance yang terjadwal. Hal ini didasarkan pada prinsip bahwa keandalan dari peralatan dan struktur dari kinerja yang akan dicapai adalah fungsi dari perancangan (design) dan kualitas pembentukan preventive maintenance yang efektif akan menjamin terlaksananya desain keandalan dari peralatan [2].

\section{Tinjauan pustaka}

\section{Pola distribusi data dalam keandalan}

Untuk mengetahui pola data yang terbentuk, maka digunakan 4 macam distribusi. Distribusi tersebut adalah distribusi normal, lognormal, weibull, dan eksponensial [4].

1. Distribusi normal

Distribusi normal atau biasa disebut distribusi Gaussian merupakan salah satu jenis distribusi yang paling sering digunakan untuk menjelaskan penyebaran data. Probability Density Function (PDF) dari distribusi normal adalah simetris terhadap nilai rata-rata (mean). Dispersi terhadap nilai rata-rata distribusi normal diukur berdasarkan nilai standar deviasi. Dengan kata lain parameter distribusi normal adalah mean dan standar deviasi. PDF dari distribusi normal dapat ditulis seperti persamaan [4]:

$$
f(t)=\frac{1}{\sigma \sqrt{2 \pi}} \exp \left[-\frac{1}{2}\left(\frac{t-\mu}{\sigma}\right)^{2}\right]
$$

Jika distribusi waktu antar kegagalan suatu sistem mengikuti distribusi normal, maka :

a. Fungsi keandalan distribusi normal adalah:

$$
R(t)=1-\Phi\left(\frac{t-\mu}{\sigma}\right)
$$

b. Laju kegagalan distribusi normal adalah: 


$$
\lambda(t)=\frac{\exp \left[-(t-\mu)^{2} / 2 \sigma^{2}\right]}{\int_{t}^{\infty} \exp \left[-(t-\mu)^{2} 2 \sigma^{2}\right] d t}
$$

2. Distribusi lognormal

Pada saat variabel acak $\mathrm{T}$ (waktu kegagalan) mempunyai distribusi lognormal, logaritma $\mathrm{T}$ memiliki distribusi normal. Fungsi kerapatan peluang untuk distribusi lognormal ditunjukkan pada persamaan [4]:

$$
f(t)=\frac{1}{\sigma t \sqrt{2 \pi}} \exp \left[-\frac{1}{2}\left(\frac{\operatorname{In} t-\mu}{\sigma}\right)^{2}\right]
$$

Karakteristik distribusi lognormal memiliki dua parameter, yaitu parameter lokasi ( $\mu$ ) dan parameter skala ( $\sigma$ ), sama dengan standar deviasi. Jika distribusi waktu antar kegagalan mengikuti distribusi lognormal, maka [10]:

a. Fungsi keandalan distribusi lognormal adalah:

$$
R(t)=1-\int_{0}^{t} \frac{1}{\sigma t \sqrt{2 \pi}} \exp \left[-\frac{1}{2}\left(\frac{\operatorname{In} t-\mu}{\sigma}\right)^{2}\right] d t
$$

b. Laju kegagalan distribusi lognormal adalah:

$$
\lambda(\mathrm{t})=\frac{f(t)}{R(t)}
$$

c. Waktu rata-rata kegagalan distribusi lignormal adalah :

$$
\text { MTTF }=\exp \left(\mu+\frac{\sigma^{2}}{2}\right)
$$

3. Distribusi Weibull

Distribusi ini merupakan distribusi yang paling sering digunakan untuk menganalisa data kerusakan, karena distribusi weilbull dapat memenuhi beberapa periode kerusakan yang terjadi, yaitu periode awal (early failure), periode normal dan periode pengausan (wear out). Periode tersebut tergantung dari nilai parameter bentuk fungsi distribusi weilbull.

Distribusi weilbull mempunyai laju kerusakan menurun untuk $\beta<1$, laju kerusakan konstan $\beta=1$ dan laju kerusakan naik $\beta>1$.

Fungsi-fungsi distribusi weilbull adalah sebagai berikut :

a. Fungsi kepadatan kerusakan :

$$
f(t)=\frac{\beta}{\alpha}\left(\frac{t}{\alpha}\right)^{\beta-1} e\left[-\left(\frac{t}{\alpha}\right)^{\beta}\right]
$$

Dimana untuk $\mathrm{t}>0$

$\alpha=$ parameter skala dengan $\alpha>0$

$\beta=$ paremeter bentuk dengan $\beta>0$ b. Fungsi distribusi kumulatif :

$$
F(t)=1-R(t)=1-e^{\left[-\left(\frac{t}{\alpha}\right)^{\beta}\right]}
$$

c. Fungsi kehandalan :

$$
R(t)=e^{\left[-\left(\frac{t}{\alpha}\right)^{\beta}\right]}
$$

d. Fungsi laju kerusakan :

$$
r(t)=\frac{f(t)}{R(t)}=\frac{\beta}{\alpha}\left(\frac{t}{\alpha}\right)^{\beta-1}
$$

Penambahan nilai $\beta$ akan mengakibatkan distribusi weillbull ekuivalen dengan distribusi tertentu, akibatnya sering digunakan sebagai penekatan untuk mengetahui karakteristik fungsi kerusakan. Hal ini dapat dilihat pada perubahan nilai $\beta$ sebagai berikut :

\begin{tabular}{|c|c|}
\hline Nilai & Laju Kerusakan \\
\hline $0<\beta<1$ & $\begin{array}{l}\text { Laju kerusakan menurun (deceasing failure } \\
\text { rate) DFR }\end{array}$ \\
\hline$\beta=1$ & $\begin{array}{l}\text { Laju kerusakan konstan (constant failure rate) } \\
\text { CFR } \\
\text { Distribusi Eksponensial }\end{array}$ \\
\hline $1<\beta<2$ & $\begin{array}{l}\text { Laju kerusakan meningkat (increasing failure } \\
\text { rate) IFR } \\
\text { Kurva berbentuk konkaf }\end{array}$ \\
\hline$\beta<2$ & $\begin{array}{l}\text { Laju kerusakan linear (linear failure rate) } \\
\text { LFR } \\
\text { Distribusi Reyleigh }\end{array}$ \\
\hline$\beta>2$ & $\begin{array}{l}\text { Laju kerusakan meningkat (increasing failure } \\
\text { rate) IFR } \\
\text { Kurva berbentuk konveks }\end{array}$ \\
\hline $3=\beta=4$ & $\begin{array}{l}\text { Laju kerusakan meningkat (increasing failure } \\
\text { rate) IFR } \\
\text { Kurva berbentuk simetris } \\
\text { Distribusi Normal }\end{array}$ \\
\hline
\end{tabular}

1. Distribusi weilbull ekuivalen dengan distribusi eksponential, jika $\beta=1$

2. Distribusi weilbull ekuivalen dengan distribusi hypereksponential, jika $\beta=0$

3. Distribusi weilbull ekuivalen dengan distribusi normal, jika $\beta<4$

Tabel 1. Nilai parameter bentuk $(\beta)$ Distribusi Weilbull [5,9].

Adapun langkah-langkah perhitungan untuk menentukan nilai-nilai parameter distribusi weilbull dua parameter adalah sebagai berikut :

a. Untuk menaksir parameter $\alpha$ dan parameter $\beta$, dapat dilakukan dengan cara pendekatan Linear Regresi. Misalkan t1, t2, t3,.....,tn adalah sejumlah data waktu antar kerusakan sistem yang telah disusun menurut urutan terkecil, untuk setiap ti $(i=1,2$, $3, \ldots \ldots . n)$ berlaku hubungan berikut : 


$$
\begin{aligned}
& \mathrm{Xi}=\mathrm{In} \mathrm{t} \\
& \mathrm{Yi}=\operatorname{In}\left[n \frac{1}{1-F(t i)}\right]
\end{aligned}
$$

Dimana :

$\mathrm{F}(\mathrm{ti})=\left[\frac{i-0.5}{N}\right]$

Setelah itu dengan menggunakan metode Least Square, nilai konstan $\alpha$ dan $\beta$ dapat diperoleh sebagai berikut :

$$
\begin{aligned}
& \mathrm{b}=\frac{N \Sigma X i . Y i-(\Sigma X i)(\Sigma Y i)}{N\left(\Sigma X i^{2}\right)-(\Sigma X i)^{2}} \\
& \mathrm{a}=\frac{\Sigma Y i}{N}-b \frac{\Sigma X i}{N}
\end{aligned}
$$

Dengan diketahui nilai kedua konstanta a dan b, maka parameter distribusi weibull dapat ditentukan yaitu :

Dimana :

$$
\mathrm{a}=e^{-\alpha / \beta} \quad \beta=\mathrm{b}
$$

$$
\begin{aligned}
& \mathrm{e} \quad=2,718 \\
& \mathrm{t}=\text { waktu terjadi kerusakan } \\
& \alpha=\text { characteristic life }(\mathrm{CL}) \\
& \beta=\text { probabilitas kumulatif dan }
\end{aligned}
$$

waktu terjadi kerusakan sebelum atau sama dengan $\mathrm{t}$

$f(t)=$ fungsi padat distribusi frekuensi

Dengan metode di atas yang digabungkan dengan metode pengujian distribusi kerusakan maka akan didapat nilai parameter fungsi kerusakan. Setelah diketahui nilai-nilai parameter distribusinya, maka perhitungan fungsi distribusi dan ongkos perawatan akan diketahui, kemudian akan didapatkan interval waktu yang optimum untuk melakukan perawatan dan penggantian pencegahan dengan meminimasi ongkos yang terjadi.

4. Distribusi Ekponensial

PDF distribusi eksponensial ditunjukkan pada Persamaan

$$
f(t)=\lambda \mathrm{e}^{-\lambda(t-\gamma)}, t>0, \lambda>0, \mathrm{t} \geq \gamma
$$

Jika distribusi waktu antar kegagalan suatu sistem mengikuti distribusi eksponensial, maka [5] :

a. Fungsi keandalan distribusi eksponensial adalah:

$$
R(t)=\mathrm{e}^{-\lambda(t \gamma)}
$$

b. Laju kegagalan distribusi eksponensial adalah:

$$
\lambda(t)=\lambda
$$

c. Waktu rata-rata kegagalan distribusi eksponensial adalah

$$
\mathrm{MTTF}=\gamma+\frac{1}{\lambda}
$$

\section{Identifikasi distribusi TTF dan TTR}

Nilai Tengah Kerusakan

$$
\begin{aligned}
& F\left(t_{i}\right)=\frac{i-0,3}{n+0,4} \\
& r=\frac{n \sum_{i=1}^{n} x_{i} \cdot y_{i}-\left(\sum_{i=1}^{n} x_{i}\right)\left(\sum_{i=1}^{n} y_{i}\right)}{\sqrt{\left[n\left(\sum_{i=1}^{n} x_{i}{ }^{2}\right)-\left(\sum_{i=1}^{n} x_{i}\right)^{2}\right]\left[n\left(\sum_{i=1}^{n} y_{i}{ }^{2}\right)-\left(\sum_{i=1}^{n} y_{i}\right)^{2}\right]}}
\end{aligned}
$$

Distribusi yang terpilih adalah distribusi yang memiliki Index Of Fit (koefisien korelasi) terbesar. Tujuan dari korelasi ini adalah untuk mencari hubungan antara variabel. Yang kemudian hasil dari penentuan distribusi ini lewat proses korelasi, kemudian akan dihitung parameter distribusinya sesuai dengan jenis distribusi yang terpilih.

\section{Mean Time to Failure (MTTF)}

Mean Time to Failure (MTTF) adalah rata-rata selang waktu kerusakan dari distribusi kerusakan dan digunakan untuk memprediksi atau mempertimbangkan terjadinya suatu kerusakan saat suatu mesin atau suatu sistem berjalan normal. Di bawah ini adalah nilai MTTF untuk masing-masing distribusi [5]):

1. Distribusi Normal

$$
M T T F=\mu
$$

2. Distribusi Lognormal

$$
M T T F=t_{m e d} \cdot e^{\frac{s^{2}}{2}}
$$

3. Distribusi Weibull

$$
\text { MTTF }=\theta \Gamma\left(1+\frac{1}{\beta}\right)
$$

nilai $\Gamma\left(1+\frac{1}{\beta}\right)$ didapat dari $\Gamma(x)=$ tabel fungsi gamma

4. Distribusi Eksponensial

$$
M T T F=\frac{1}{\lambda}
$$

\section{Mean Time to Repair (MTTR)}

Mean Time to Repair (MTTR) adalah rata-rata selang waktu kerusakan dari probabilitas waktu perbaikan dan digunakan untuk memprediksi atau mempertimbangkan dilakukannya suatu perbaikan saat kerusakan terjadi. Di bawah ini adalah nilai MTTR untuk masingmasing distribusi [5]: 
1. Distribusi Normal

$$
M T T R=\mu
$$

2. Distribusi Lognormal

3. Distribusi Weibull

$$
M T T R=t_{\text {med }} \cdot e^{\frac{s^{2}}{2}}
$$

$$
\operatorname{MTTR}=\alpha \Gamma\left(1+\frac{1}{\beta}\right)
$$

nilai $\Gamma\left(1+\frac{1}{\beta}\right)$ didapat dari $\Gamma(x)=$ tabel fungsi gamma.

4. Distribusi Eksponensial

$$
\operatorname{MTTR}=\frac{1}{\lambda}
$$

\section{Metode Penelitian}

\section{Studi literatur}

Studi literatur akan digunakan untuk mendapatkan kajian secara teoritis, mengetahui motode yang dapat digunakan untuk menyelesaikan permasalahan dalam penelitian ini. Teoti - teori yang akan digunakan meliputi teori tentang Reliability Centered Maintenence (RCM), teori kehandalan (reliability). Selain ini juga dilakukan studi terhadapat penelitianpenelitian yang telah ada sebelumnya yang dapat dijadikan sebagai pertimbangan dan acuan bagi penelitian yang dilakukan $[7,8]$.

\section{Studi lapangan}

Studi Lapangan dilakukan untuk mengamati objek yang akan diteliti. Dari hasil pengamatan dilapangan akan diketahui aliran proses produksi, serta kondisi sebenarnya dari Main gas admission valve. Dari studi lapangan diharapkan dapt diperoleh tentang pendekatan yang sesuai untuk pelaksanaan penelitian.

\section{Tahap identifikasi dan perumusan masalah}

Tahap ini bertujuan untuk memaparkan latar belakang masalaha yang mau diangkat dalam penelitian, merumuskan masalah sebagai bahan yang akan dibahas dalam penelitian, menentukan tujuan yang akan dicapai, serta menentukan asumsi dan batasan yang akan membantu dalam penyelesaian masalah dalam penelitian.

a. Pengumpulan Data
Pada tahap ini dilakukan pengumpulan data yang diambil di PT TELKOMSEL area Cluster Network Operation yang dibutuhkan untuk menunjang penelitian ini. Data penunjang sebagai berikut:

1. Detail dari komponen yakni fungsi, keterkaitan dengan komponen lain, kegagalan fungsi yang mungkin terjadi, bentuk kegagalan, efek yang ditimbulkan akibat kegagalan.

2. Data waktu antar kerusakan dan data waktu antar perbaikan.

3. Data biaya operasional, biaya tenaga kerja, biaya spare part, dan biaya perawatan.

4. Sumber Data

Sumber data primer didapatkan dengan beberapa cara diantaranya adalah wawancara langsung dengan bagian operator dan teknisi pemeliharaan mesin diesel genset. Selain dari hasil wawancara, data primer juga didapat dari data kerusakan peralatan selama periode Januari 2017 sampai dengan Januari 2020. Untuk data sekunder didapatkan melalui beberapa kajian literatur diantaranya adalah jurnal teknik, penelitian sebelumnya, buku serta jurnal teknik mengenai Mesin Diesel Genset dan juga Reliability Centered Maintenance (RCM) untuk membantu memecahkan masalah dalam penelitian.

b. Pengolahan Data

Data- data yang telah terkumpul tersebut kemudian diolah baik secara kualitatif maupun kuantitatif. Yakni

1. Mengumpulkan data- data kerusakan line gas mesin wartsila yang terjadi dari tahun $2014-2016$.

2. Data kerusakan tersebut dimasukkan ke dalam form FMEA. Dan selanjutnya dimasukkan ke dalam kolom Reliability Centered Maintenance (RCM) [10].

3. Melakukan uji distribusi data, menghitung parameter Weibull.

4. Menghitung reliability dan laju kegagalan.

5. Menganalisa karakteristik kegagalan, laju kerusakan. 
6. Sehingga dihasilkan jenis pemeliharaan.

\section{Waktu dan Tempat Penelitian}

Penelitian ini dilakukan di PT TELKOMSEL area Cluster Network Operation RTPO Tembilahan. Penelitian pada object penilitian yaitu peralatan Mesin Diesel Genset Deutz 20kVA dilakukan selama \pm 3 Bulan, yaitu dimulai pada Bulan Mei hingga Juli 2020.

\section{Alur penelitian}

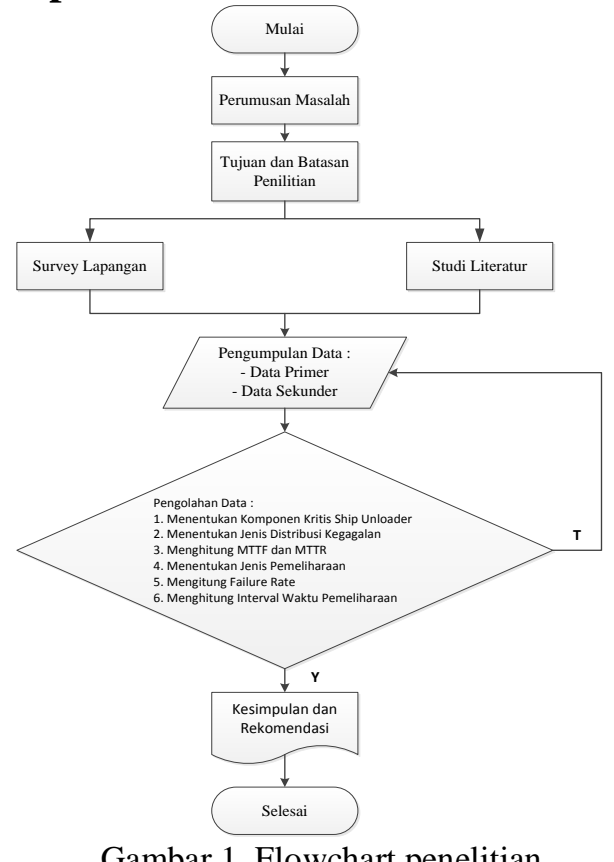

Hasil dan Pembahasan

Penentuan waktu perbaikan (TTR) dan kerusakan (TTF)

Tabel 2. Data selang waktu antar kerusakan dan failure time komponen Alternator.

\begin{tabular}{|c|c|c|c|c|c|}
\hline \multirow{2}{*}{$\mathrm{NO}$} & \multirow{2}{*}{$\begin{array}{c}\begin{array}{c}\text { Waktu } \\
\text { kerusakan }\end{array} \\
\text { Tanggal }\end{array}$} & \multirow{2}{*}{$\begin{array}{c}\begin{array}{c}\text { Waktu } \\
\text { antar } \\
\text { kerusakan }\end{array} \\
\text { Jam }\end{array}$} & \multicolumn{2}{|c|}{ Waktu perbaikan } & \multirow{2}{*}{$\begin{array}{c}\begin{array}{c}\text { Failure } \\
\text { time }\end{array} \\
\text { Jam }\end{array}$} \\
\hline & & & $\begin{array}{c}\text { Start } \\
\text { Repair }\end{array}$ & $\begin{array}{c}\text { Start } \\
\text { operasi }\end{array}$ & \\
\hline 1 & $\begin{array}{c}5 / 1 / 17 \\
19: 00\end{array}$ & 609 & $\begin{array}{l}7 / 1 / 17 \\
21: 00\end{array}$ & $\begin{array}{l}\text { 8/1/17 } \\
21: 00\end{array}$ & 24 \\
\hline 2 & $\begin{array}{c}3 / 2 / 17 \\
6: 00\end{array}$ & 7901 & $\begin{array}{c}5 / 2 / 17 \\
6: 00 \\
\end{array}$ & $\begin{array}{c}6 / 2 / 17 \\
9: 00 \\
\end{array}$ & 27 \\
\hline 3 & $\begin{array}{l}1 / 1 / 18 \\
14: 00\end{array}$ & 5310 & $\begin{array}{l}1 / 1 / 18 \\
19: 00\end{array}$ & $\begin{array}{c}2 / 1 / 18 \\
14: 00\end{array}$ & 19 \\
\hline 4 & $\begin{array}{c}11 / 8 / 18 \\
6: 00\end{array}$ & 3023 & $\begin{array}{c}13 / 8 / 18 \\
13: 00\end{array}$ & $\begin{array}{c}14 / 8 / 18 \\
9: 00\end{array}$ & 20 \\
\hline 5 & $\begin{array}{c}18 / 12 / 18 \\
8: 00\end{array}$ & 336 & $\begin{array}{l}\text { 20/12/1 } \\
811: 00 \\
\end{array}$ & $\begin{array}{l}21 / 12 / 1 \\
811: 00 \\
\end{array}$ & 24 \\
\hline 6 & $\begin{array}{l}4 / 1 / 19 \\
11: 00\end{array}$ & 2240 & $\begin{array}{l}4 / 1 / 19 \\
21: 00\end{array}$ & $\begin{array}{l}5 / 1 / 19 \\
17: 00\end{array}$ & 20 \\
\hline 7 & $\begin{array}{c}9 / 4 / 19 \\
1: 00\end{array}$ & 2240 & $\begin{array}{c}12 / 4 / 19 \\
1: 00\end{array}$ & $\begin{array}{c}13 / 4 / 19 \\
1: 00\end{array}$ & 24 \\
\hline 8 & $\begin{array}{c}14 / 12 / 19 \\
7: 00\end{array}$ & 5886 & $\begin{array}{l}\text { 14/12/1 } \\
922: 00\end{array}$ & $\begin{array}{l}\text { 15/12/1 } \\
918: 00\end{array}$ & 20 \\
\hline
\end{tabular}

Perhitungan Mean Time to Repair (MTTR)

Untuk menghitung nilai Mean Time To Repair (MTTR) terlebih dahulu melakukan perhitungan nilai index of fit $(r)$ failure time. Untuk menentukan index of fit (r) dilakukan dengan menggunakan 4 distribusi, yaitu distribusi Normal, LogNormal, Eksponensial, dan Weibull.

Sehingga perhitungan index of fit $(\boldsymbol{r})$ yang didapat dari beberapa perhitungan distribusi adalah sebagai berikut :

Tabel 3. Data nilai index of fit (r) failure time

\begin{tabular}{cc}
\hline Distribusi & Index of Fit $(\boldsymbol{r})$ \\
\hline Normal & 0,7909597 \\
\hline Lognormal & 0,7212118 \\
\hline Eksponensial & 0,6056875 \\
\hline Weibull & 0,8035823 \\
\hline
\end{tabular}

Untuk mengetahui distribusi yang terpilih maka dapat dilihat dari nilai index of fit $(r)$ atau koefisien korelasi yang terbesar, dari Tabel 3 diketahui nilai index of fit $(r)$ terbesar diperoleh oleh distribusi Weibull yaitu 0,8035823 .

\section{Perhitungan \\ Parameter distribusi terpilih}

Setelah distribusi perbaikan Alternator diketahui, maka langkah selanjutnya adalah menghitung parameter distribusi weibull yaitu $a$ dan $b$. Berikut perhitungan parameter distribusi weibull untuk Alternator :

Perhitungannya sebagai berikut :

$\alpha=e^{\left(-\frac{a}{b}\right)}=e^{\left(-\frac{-5.29835}{1.64205}\right)}=25,19562 \mathrm{jam}$

$\beta=b=1,64205$

\section{Nilai Mean Time to Repair (MTTR)}

Perhitungan waktu rata-rata antar perbaikan dilakukan terhadap Alternator menggunakan distribusi Weilbull.

Dari perhitungan Mean Time To Repair (MTTR) untuk komponen Alternator memiliki waktu rata-rata perbaikan sebesar 22,54 jam, yang artinya rata-rata waktu untuk perbaikan komponen Alternator yaitu 22,54 jam. Dari waktu tersebut bisa digunakan untuk menentukan 
interval pemeliharaan yang bertujuan sebagai susunan pemeliharaan terjadwal atau penggantian komponen sebelum komponen tersebut mengalami kerusakan penuh.

\section{Perhitungan Mean Time to Failure (MTTF)}

Untuk menghitung nilai Mean Time

To Failure (MTTF) terlebih dahulu menghitung nilai index of fit $(r)$ data waktu antar kerusakan. Terdapat 4 distribusi yang dipakai dalam menentukan index of fit $(r)$, yaitu distribusi normal, lognormal, eksponensial, dan weibull.

Sehingga perhitungan index of fit $(r)$ yang didapat dari beberapa perhitungan distribusi adalah sebagai berikut :

Tabel 4. Data nilai index of fit (r) data waktu antar kerusakan

\begin{tabular}{lc}
\hline Distribusi & Index of Fit $(\boldsymbol{r})$ \\
\hline Normal & 0,97900 \\
\hline Lognormal & 0,95216 \\
\hline Eksponensial & 0,96491 \\
\hline Weibull & 0,88242 \\
\hline
\end{tabular}

Untuk mengetahui distribusi yang terpilih maka dapat dilihat dari nilai index of fit $(r)$ atau koefisien korelasi yang terbesar, dari Tabel 5 diketahui nilai index of fit $(r)$ terbesar diperoleh oleh distribusi normal yaitu 0,97900 . Sehingga rumus parameter yang digunakan untuk melakukan perhitungan MTTF dari distribusi Normal adalah :$$
M T T F=\mu
$$ \\ Perhitungan parameter distribusi terpilih}

Setelah distribusi kerusakan Alternator diketahui, maka Langkah selanjutnya adalah menghitung parameter distribusi Normal, untuk mencari nilai MTTF terlebih dahulu menghitung nilai dari mean $(\mu)$. Berikut perhitungan parameter distribusi untuk Alternator:

$$
\sigma=\sqrt{\frac{(763244868)^{2}}{7-1}}=11278,629
$$

Nilai Mean Time to Failure (MTTF)

Perhitungan waktu rata-rata antar kerusakan dilakukan terhadap Alternator menggunakan distribusi Normal.
Dari perhitungan MTTF untuk komponen Alternator memiliki waktu ratarata antar kerusakannya sebesar 25305 jam, yang artinya komponen alternator akan mengalami kerusakan kembali setelah beroperasi selama 25305 jam $\approx 1054$ hari $\approx 35$ Bulan.

\section{Penentuan jenis pemeliharaan Alternator \\ Dalam menentukan jenis} pemeliharaan Alternator sangat dipengaruhi oleh nilai $\beta$ (parameter bentuk) pada distribusi kerusakan yang terjadi. Dari perhitungan di Distribusi Weibull sebelumnya didapatkan nilai $\beta$ sebesar 1,64205. Sehingga berdasarkan tabel Decrising Failure Rate (DFR) dan Eksponential Distribution (CFR) jika nilai $\beta>1$, maka jenis pemeliharaan yang sesuai adalah Preventive dan Time Based.

\section{Penentuan interval waktu pemeliharaan alternator}

Pemeriksaan bertujuan untuk mengetahui apakah suatu komponen atau peralatan masih dalam keadaan baik atau perlu dilakukannya perbaikan atau penggantian. Dibawah adalah formulasi menghitung interval waktu pemeriksaan yang bertujuan untuk membuat suatu susunan jadwal pemeliharaan atau penggantian komponen sebelum komponen tersebut mengalami kerusakan penuh. Berikut ini adalah perhitungan interval waktu yang optimal untuk pemeliharaan Alternator:

1. Jumlah waktu pemeriksaan $(k)$ Jumlah kerusakan Alternator selama 36 bulan $=8$ kali $k=0,22$

2. Waktu rata-rata yang dibutuhkan untuk perbaikan $(\mu)$

$$
\begin{gathered}
M T T R=22,54 \mathrm{jam} \\
\mu=\frac{t}{M T T R}=\frac{720}{22,54}=31,94 \mathrm{jam}
\end{gathered}
$$

3. Waktu rata-rata untuk melakukan pemeriksaan $(i)$

Waktu untuk melakukan pemeriksaan

$$
\left(t_{i}\right)=i=\frac{t}{t_{i}}=\frac{720}{0,5}=1440 \mathrm{jam}
$$


4. Perhitungan frekuensi dan interval pemeriksaan $(n)$

$$
\begin{aligned}
& n=\sqrt{\frac{k . i}{\mu}}=\sqrt{\frac{0,22 \times 1440}{31,94}}=3,165 \\
& \text { pemeriksaan/bulan }
\end{aligned}
$$

5. Interval waktu pemeriksaan $=\frac{t}{n}=$ $\frac{720}{3.165}=227,48694$ jam $\approx 9$ hari

\section{Perhitungan nilai Reliability (Kehandalan) Alternator}

Nilai kehandalan pada komponen Alternator dapat dihitung dengan menggunakan rumus berikut.

$$
\mathrm{R}(\mathrm{t})=1-\mathrm{F}(\mathrm{t})
$$

$\mathrm{F}(\mathrm{t})=$ Cumulative Distribution Function (CDF)

$\mathrm{R}(\mathrm{t})=$ Reliability Function

$\mathrm{f}(\mathrm{t})=$ Probability Density Function (PDF)

Untuk menghitung nilai Probability

Density Function $[f(t)]$, Cummulative Distribution Function $[F(t)]$, dan Reliability Function $[R(t)]$ bisa dicari dengan menggunakan Microsoft Excel. Rumus yang digunakan adalah sebagai berikut :

1. Fungsi Kepadatan Probabilitas/ Probability Density Function $[f(t)]=$ NORM.DIST

2. Fungsi Distribusi Kumulatif/ Cummulative Distribution Function $[F(t)]=$ NORM.DIST

3. Fungsi Keandalan / Reliability Function $[R(t)]$

$$
R(t)=1-F(t)
$$

Dengan menggunakan persamaan diatas pada Microsoft Excel, maka didapatkan hasil / Nilai Reliability (Kehandalan) pada komponen alternator seperti Tabel 5.

Tabel 5. Nilai Kehandalan pada komponen Alternator

\begin{tabular}{ccccc}
\hline \multirow{2}{*}{$\mathbf{t}$} & $\mathbf{F}(\mathbf{t})$ & \multirow{2}{*}{$\mathbf{R}(\mathbf{t})$} & $\mathbf{f}(\mathbf{t})$ & \multirow{2}{*}{ failure rate } \\
\cline { 2 - 3 } & $\mathbf{C D F}$ & & $\mathbf{P D F}$ & \\
\hline 1 & 0.000796 & 0.999204 & 0.000701 & 0.00070118 \\
\hline 2 & 0.001465 & 0.998535 & 0.000644 & 0.00064542 \\
\hline 3 & 0.002093 & 0.997907 & 0.000614 & 0.00061488 \\
\hline 4 & 0.002695 & 0.997305 & 0.000592 & 0.00059409 \\
\hline 5 & 0.00328 & 0.99672 & 0.000577 & 0.00057845 \\
\hline 6 & 0.00385 & 0.99615 & 0.000564 & 0.00056597 \\
\hline 7 & 0.004408 & 0.995592 & 0.000553 & 0.00055564 \\
\hline
\end{tabular}

Bila variabel acak dinyatakan sebagai suatu waktu kegagalan atau umur komponen maka fungsi kehandalan dinotasikan dengan $R(t)$ memiliki range $0<R(t)<1$, dimana:

$R=1$, sistem dapat melaksanakan fungsi dengan baik.

$R=0$, sistem tidak dapat melaksanakan fungsi dengan baik.

Dari nilai yang diperoleh pada Tabel 5, maka Alternator dikatakan masih memiliki fungsi dengan baik karena interval nilai nya masih di range $0<$ $R(t)<1$.

Tabel 6. Nilai Parameter Kehandalan pada komponen Alternator

\begin{tabular}{ccc}
\hline No & Parameter & Nilai \\
\hline 1 & $\lambda(\mathrm{t})=(\mathrm{f}(\mathrm{t})) /(\mathrm{R}(\mathrm{t})$ & 0,00000285873 \\
2 & $\mathrm{MTTF} / \mu$ & 25305 \\
3 & $f(\mathrm{t})$ & 0,0000028587 \\
4 & $\mathrm{~F}(\mathrm{t})$ & 0,0124483084 \\
5 & $\mathrm{R}(\mathrm{t})$ & 0,9999971413 \\
\hline
\end{tabular}

Selama waktu operasi mesin yaitu jam kerja, selama 3 tahun terjadi perawatan korektif sebanyak 7 kali. Dari perhitungan diperoleh laju kerusakan $\chi=$ 0,0000028587330 jam. Waktu rata - rata diantara kerusakan $(\mathrm{MTTF})=25305$ jam, artinya mesin akan mengalami kerusakan kembali setelah beroperasi rata-rata 25305 jam. Fungsi kepadatan kegagalan $\mathrm{f}(\mathrm{t})=$ 0,0000028587 dan fungsi distribusi kumulatif $F(t)=0,0124483084$ sering juga disebut fungsi ketidakhandalan. Jadi nilai kehandalan dapat diketahui $\mathrm{R}(\mathrm{t})=$ 0,9999971413. Kehandalan komponen alternator ini termasuk baik, karena nilai keandalannya diatas $90 \%$ dan mendekati $100 \%$ sehingga komponen tersebut jarang mengalami kerusakan.

\section{Perhitungan laju kerusakan (failure} rate) Alternator

Laju kerusakan $(\lambda)$ adalah banyaknya kegagalan per satuan waktu. Laju kerusakan dapat dinyatakan sebagai perbandingan antara banyaknya kegagalan yang terjadi selama selang waktu tertentu dengan total waktu operasi komponen atau sistem. Berikut rumus menghitung laju kerusakan/failure rate: 
Laju Kerusakan/ Failure Rate $(\lambda)$

$$
\lambda=\frac{f(t)}{R(t)}
$$

Untuk menghitung

laju

kerusakan/failure rate terlebih dahulu menghitung Probability Density Function $[f(t)]$, Cummulative Distribution Function $[F(t)]$, dan Reliability Function $[R(t)]$. Dengan menggunakan perhitungan sebelumnya di nilai kehandalan, maka didapatkan hasil seperti gambar grafik di bawah ini :

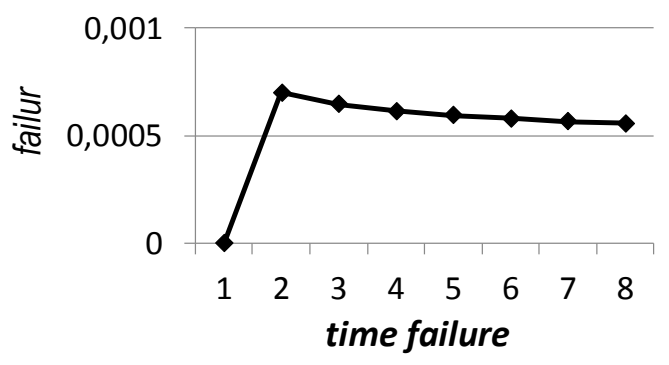

Gambar 2. Grafik Laju Kerusakan Alternator

Dari gambar 3. grafik laju kerusakan menunjukkan setiap bertambahnya periode waktu kerusakan maka laju kerusakan terus mengalami peningkatan sehingga kurva yang terbentuk meningkat atau disebut sebagai increasing failure rate (IFR). Fungsi laju kegagalan $\lambda(t)$ menunjukkan peningkatan dimana peluang kegagalan komponen selama interval waktu yang sama menjadi bertambah besar. Kegagalan ini diakibatkan oleh penuaan, korosi, gesekan, sehingga di sebut fase pengausan (wearout).

\section{Hasil Reliability Centered Maintenance Alternator}

Berdasarkan hasil analisa kerusakan mesin diesel genset Deutz PT. TELKOMSEL cluster Network Operation RTPO Tembilahan menggunakan metode Reliability Centered Maintenance (RCM) maka didapatkan hasil sebagai berikut :

Tabel 8. Hasil RCM pada Alternator

\begin{tabular}{cc}
\hline Deskripsi & Nilai \\
\hline Komponen kritis & Alternator \\
MTTF & 25305 Jam \\
$\beta$ & 1,64205 \\
Jenis pemeliharaan & Preventive dan Time Based \\
MTTR & 22,54 jam \\
Interval waktu Pemeliharaan / & 227,49 jam atau 9 hari \\
Pemeriksaan & \\
\hline
\end{tabular}

Failure Mode and Effect Analiysis (FMEA)[10]

Selanjutnya seluruh komponen Failure Mode tersebut dianalisa agar dapat diketahui lebih detail bagaimana suatu komponen dalam sistem dapat mengalami kegagalan. Selanjutnya akan dapat memungkinkan kita memberikan saran untuk waktu pelaksanaan Preventive Maintenance, atau perencanaan tindakan monitoring untuk mencegah failure rate dengan menggunakan RCM Decision Worksheet di penjelasan berikutnya.

\section{RCM Decision Worksheet}

Tindakan pemeliharaan Reactive, Inspection dan Predictive Maintenance dengan melakukan kegiatan maintenance secara terjadwal dalam jangka waktu ideal maksimal 227,49 jam atau 9 hari, dan juga memprediksi kapan akan terjadinya kerusakan pada komponen tertentu pada mesin diesel dengan cara melakukan analisa trend perilaku mesin/peralatan kerja.

\section{Perhitungan biaya kerusakan dan biaya perawatan Biaya kerusakan (Cost of Failure )}

Biaya terdiri dari biaya part alternator dan biaya kehilangan produksi.

1. Biaya Alternator

Biaya 1 pcs alternator, jika rusak maka akan diganti 1 pes part nya, maka perhitungannya sebagai berikut :

Harga/pcs : Rp. 3.000.000

Total biaya komponen : Rp. 3.000.000

2. Biaya kehilangan revenue / keuntungan didasarkan atas output dan laba yang diperoleh.

Output x 24 jam operasi $=$ Rp. 10.000 .000

Kerugian perjam $=$ Rp. $10.000 .000 / 24=$ Rp. 416.667

Karena kerusakan Alternator membutuhkan waktu 1 hari (MTTR : 22,54 Jam) untuk memperbaikinya, maka biaya kehilangan revenue / keuntungan menjadi sbb :

Biaya kehilangan revenue $=1 \mathrm{x} R \mathrm{R}$. 10.000.000 = Rp. 10.000 .000

Karena waktu failure time terbesar adalah 24 jam, dan jumlah waktu untuk perbaikan 
5 jam, maka kerugian produksi selain waktu perbaikan adalah :

Kerugian diluar waktu perbaikan $=24-5=$ 19 jam

Sehingga kerugian revenuenya $=19 \mathrm{x}$ Rp. $416.667=$ Rp. 7.916 .673

\section{Biaya penggantian ( Cost of Preventive )}

Biaya ini terdiri dari biaya pembelian komponen/part alternator dan biaya tenaga $\operatorname{kerja}(\mathrm{CM})=$ Rp. $3,000,000+$ Rp. $83,333=$ Rp. 3, 083,333.

\section{Penentuan interval CM (Corrective Maintenance)}

Biaya kegagalan adalah biaya yang timbul akibat mesin mengalami kerusakan seperti biaya penggantian komponen, dan biaya tenaga kerja perawatan. Perhitungan biaya kegagalan sebagai berikut :

$$
\mathrm{Cf}=\mathrm{CR}+\mathrm{MTTR}(\mathrm{Co}+\mathrm{CTK})
$$

Dimana :

$$
\begin{aligned}
& \mathrm{Cf}=\text { biaya kegagalan } \\
& \mathrm{CR}=\text { biaya penggantian komponen } \\
& \mathrm{Co}=\text { biaya kerugian perjam } \\
& \begin{aligned}
\mathrm{CTK} & =\text { biaya tenaga kerja perjam } \\
\mathrm{Co} & =\text { Kerugian } / \text { Lost revenue perjam } \\
& =\mathrm{Rp} .10 .000 .000 / 24 \mathrm{Jam} \\
& =\mathrm{Rp} .416 .667 / \mathrm{jam}
\end{aligned}
\end{aligned}
$$

Maka Biaya Kegagalannya sebesar :

$\mathrm{Cf}=3.000 .000+22,54$ (Rp. 416.667+ $83.333)=$ Rp. 14.270 .008

maka selanjutnya dihitung nilai interval penggantian komponen Alternator optimalnya (TM) sebagai berikut :

$$
\begin{gathered}
\mathrm{TM}=\alpha\left|\frac{C m}{C f(\beta-1)}\right|^{\wedge} \frac{1}{\beta} \\
\mathrm{TM}=25305 \\
\left|\frac{3.083 .333}{14.270 .008(1,64205-1)}\right|^{\frac{1}{1,64205}}=13036,72 \mathrm{jam}
\end{gathered}
$$

Dari perhitungan, didapatkan nilai untuk interval corrective maintenance yang sesuai untuk dilakukannya penggantian komponen Alternator adalah sebesar 13036,72 jam.

\section{Perhitungan biaya corrective maintenance saat ini dan usulan}

Biaya corrective maintenance yang dikeluarkan perusahaan saat ini pertahun adalah:
Failure cost $=$ Biaya part Alternator + Biaya Lost Revenue (selain waktu perbaikan)

a. Failure Cost $=$ Rp. $3.000 .000+R p$ 7.916.673 = Rp. 10.916.673

b. Frekuensi kerusakan. Untuk kerusakan pertahun, rata-rata kerusakan terjadi sebanyak 3 kali

c. Ongkos Corrective Maintenance saat ini (pertahun)

$$
\begin{aligned}
& =3 \times 10.916 .673 \\
& =\text { Rp. } 32.750 .019
\end{aligned}
$$

d. Ongkos Corrective Maintenance saat ini (per 5 tahun)

$$
\begin{aligned}
& =5 \times \text { Rp. } 32.750 .019 \\
& =\text { Rp. } 163.750 .095
\end{aligned}
$$$$
\text { Perhitungan biaya corrective }
$$
maintenance usulan meliputi biaya perawatan terencana (Preventive Replacement Cost) yang didasarkan pada selang waktu penggantian yang diperoleh sebelumnya. Perhitungan besarnya biaya penggantian terencana adalah :

Preventive Replacement Cost $=$ Biaya komponen

Perhitungan biaya perawatan usulan untuk komponen Alternator dengan waktu perawatan yang optimum adalah 13036,72 jam $=543$ hari

a. Preventive replacement cost untk 1 kali penggantian :

$$
=\text { Rp. } 3.000 .000
$$

b. Jumlah Interval Perawatan

- Jumlah operasi mesin periode pertahun :

$=12$ bulan $\mathrm{x} 30$ hari $=360$ hari

- Jumlah Interval Corrective Maintenance :

$=\frac{360}{543}=0,66 \mathrm{kali}$

c. Biaya Corrective Maintenance Usulan :

$=0,66 \times$ Rp. $3 \cdot 000 \cdot 000$

$=$ Rp. 1.988 .230

Dari perhitungan, waktu yang diperoleh untuk menghindari waktu breakdown yang terlalu lama dan biaya kerugian yang besar adalah dengan interval waktu pemeriksaan/ pemeliharaan (Preventive dan Time Based) 227,49 jam dan interval waktu corrective maintenance 
/penggantian komponen selama 543 hari hari dengan biaya Rp. 1.988.230 sehingga pengematan biaya adalah sebesar Rp. 30.761 .789 atau sekitar 93,93\% dari biaya saat ini yang sudah dikeluarkan sebesar Rp. 32.750.019.

\section{Kesimpulan}

Berdasarkan hasil analisa yang didapat, komponen yang frekuensinya sering mengalami kerusakan pada mesin diesel genset deutz adalah Alternator. Pemilihan ini didasarkan pada jumlah frekuensi kerusakan tertinggi serta downtime terlama selama kurang lebih 3 tahun. Dari hasil perhitungan nilai Mean Time to Failure (MTTF) Alternator adalah 25305 jam yang artinya komponen Alternator akan mengalami kerusakan kembali setelah beroperasi selama 25305 jam. Sedangkan nilai Mean Time to Repair (MTTR) dari Alternator adalah 22,54 jam yang artinya rata-rata waktu untuk perbaikan komponen Alternator selama 22,54 jam. Dari hasil perhitungan Nilai Kehandalan, Alternator dikatakan masih memiliki fungsi dengan baik karena interval nilai rata - rata nya masih di range $0<R(t)<1$. Dari hasil analisa didapat nilai $\beta$ sebesar 1,64205 . Dengan nilai tersebut $(\beta>1)$ maka jenis pemeliharaan yang sesuai pada komponen Alternator adalah Preventive dan Time Based Maintenance. Dari hasil perhitungan yang di peroleh untuk menghindari waktu breakdown yang terlalu lama dan biaya kerugian yang besar adalah dengan interval waktu pemeriksaan /pemeliharaan (Preventive dan Time Based Maintenance) 227,49 jam dan interval waktu corrective maintenance /penggantian komponen selama 543 hari hari dengan biaya Rp. 1.988.230 sehingga pengematan biaya adalah sebesar Rp. 30.761.789 atau sekitar 93,93\% dari biaya saat ini yang sudah dikeluarkan sebesar Rp. 32.750.019.

\section{Ucapan terima kasih}

Terimakasih kami ucapkan kepada prodi teknik mesin yang telah memberikan kesempatan kepada kami untuk melaksanakan penelitian dan kepada pihak yang terkait lainya.

\section{Referensi}

[1] Hezer, Jay and Render, Barry 2005, Operations Manajement, Salemba Empat

[2] Prof. Dr. H. Santoso, Gempur, Drs., M.Kes, 2010, Manajemen Perawatan Pabrik Dengan Pendekatan Ergonomis, PT. Prestasi Pustakaraya, Jakarta

[3] Assauri, S., 2008. "Manajemen Produksi dan Operasi“. Edisi Revisi. Lembaga Penerbit Fakultas Ekonomi Universitas Indonesia. Jakarta.

[4] Ahmad Kholid Alghofari, Much. Djunaidi, Amin Fauzan, 2006 Perencanaan Pemeliharaan Mesin Ballmill dengan Basis RCM (Reliability Centered Maintenance, Vol 5

[5] Ebeling Charles, 1997 An Introduction To Reliability And Maintenance Engineering. New York, USA: Waveled Press Inc

[6] Corder, Anthony, 2000, "Teknik Manajemen Pemeliharaan", Erlangga, Jakarta

[7] Sunaryo dkk, 2018, Aplikasi Reliability Centered Maintenance (RCM) Pada Sistem Saluran Gas Mesin Wartsila, Jurnal Teknik Industri Terintegrasi, 27-35

[8] Afdal dkk, 2020 Penerapan RCM Pada Kompresor Dalam Sistem Kriogenik, Jurnal Teknik Industri Terintegrasi, 16-25

[9] Akbar Prastiko, "Laju Kegagalan dan Distribusi Laju Kegagalan “. June 042017

[10] Kang, J., Sun, L., Sun, H., \& Wu, C. (2016). Risk assessment of floating offshore wind turbine based on correlation-FMEA.

Engineering, 382-388 